\title{
$\checkmark$ Research Square

\section{Three species (Hyalomma asiaticum, Rhipicephalus turanicus and H.sulcata)of ticks identified from lizards in arid desert regions of Xinjiang}

\section{Qi Zhou}

Sichuan University

Jiao Li

Sichuan University

\section{Xianguang Guo}

University of the Chinese Academy of Sciences

Jinlong Liu

University of the Chinese Academy of Sciences

Qi Song

University of the Chinese Academy of Sciences

\section{Xiong Gong}

University of the Chinese Academy of Sciences

\section{Han Chen}

Sichuan University

Jianhui Zhang

Sichuan University

Jinlei He

Sichuan University

\section{Zhiwan Zheng}

Sichuan University

\section{Dali Chen}

Sichuan University

Jian-Ping Chen ( $\sim$ jpchen007@163.com )

Department of Pathogenic Biology, West China School of Basic Medical Sciences and Forensic Medicine, Sichuan University, Chengdu, China

\section{Research}

Keywords: Ticks, Lizards, Xinjiang, Phylogenetic relationships

Posted Date: July 2nd, 2020 
DOI: https://doi.org/10.21203/rs.3.rs-39441/v1

License: (a) (i) This work is licensed under a Creative Commons Attribution 4.0 International License. Read Full License 


\section{Abstract \\ Background}

Ticks are obligate hematophagous ectoparasites of vertebrate animals including human with wide distribution over the world, which are vectors of some human diseases. To date, the species discrimination and phylogenetic relationships among ticks on lizards in China are still unclear. The morphological method is not sufficient for identification of damaged, engorged or immature specimens by the loss of morphological criteria or by the lack of morphological criteria. So, Molecular technique was applied tothis study.

\section{Methods}

In this study, the 12S, 16S rDNA and COI fragments of 31 ticks collected from Eremias multiocellata-lizard from 4 arid desert regions of Xinjiang Uygur Autonomous regions in China, were sequenced. 47 Chinese ticks from hedgehog and 1 tick from brushwood were included in this study as reference sample. To infer the phylogenetic relationships among them, 66 12S rDNA, 104 16S rDNA and $85 \mathrm{COI}$ sequences of ticks retrieved from GenBank were also included. All samples identified with phylogenetic and network analyses.

\section{Results}

The three Bayesian analyses results (12S, 16S rDNA and COI fragments ) are consistent. They revealed that the 31 ticks from lizards belong to 3 genus and 3 species: 11 were identified as Hyalomma asiaticum, 3 as Rhipicephalus turanicus and 17 ticks belong to Haemaphysalis sulcata. Our results also indicated that the collected ticks from hedgehog were identified as Hyalomma asiaticum (38) and Rhipicephalus turanicus (9), the tick from brushwood was identified as Hyalomma asiaticum. All of these ticks collected from lizard were in small size ranged from 1 to $2 \mathrm{~mm}$. Besides, some of these ticks share the same genotype with their counterparts in neighboring countries. The characteristics of ticks found in this study in Xinjiang may be closely related to the geographical environment.

\section{Conclusions}

Our study is the first attempt to investigate the ticks on lizards from the arid desert regions of Xinjiang in China, all of the discoveries on ticks in this study is closely related to the geographical environment in Xinjiang. which would provide more information to the control of ticks and tick-borne pathogens in the northern China.

\section{Background}


Ticks are obligate hematophagous ectoparasites of vertebrate animals including human with wide distribution over the world [1, 2], which are considered to be the second worldwide vectors of human diseases, just less than mosquitoes. They are part of the suborder Ixodida which comprises three families: Argasidae, Ixodidae, and Nuttalliellidae [3]. In China, ticks have high species diversity and have been divided into 2 families (Argasidae and Ixodidae) and about 120 species [4, 5]. Among the 120 identified species, more than 40 species were confirmed to be distributed in Xinjiang Uygur Autonomous region [6].

All kinds of terrestrial vertebrates, including reptiles, birds, mammals and even amphibians, are considered as ideal hosts for ticks [7]. A comprehensive study had been undertaken on the ectoparasitic ticks on domestic animals. In the early study by Wang et al., ticks from livestock in Northern Xinjiang were identified four genera and seven species [8]. In India, Balasubramanian et al. found that 168 of 195 detected cattle were infested by ticks, which comprised 3 genera and 7 species [9]. So far, despite numerous studies focused on ticks, it is a great pity that few studies were undergone about ticks in wild animals, especially in China. In a survey on the relationship about ticks and hosts, Mihalca et al. identified 6 species of ticks on hedgehogs in Romania [10]. Cerdena et al. found A. parvitarsum-a hard tick on the liolaemus lizards in Peru for the first time [11]. Additional, as wild animals commonly share the same habitats with domestic animals and human beings, tick-associated agents carried by wild-animals might infect domestic animals and eventually result in human infections $[9,12]$. Xinjiang, a province with developed animal husbandry [13] and have lizards widely distributed. Meanwhile, more and more people choose lizards to their pet. Thus, information on the phylogenetic relationships and the species composition about ticks in wild animals is imperative to control ticks and tick-borne disease.

Traditionally, the identification of ticks is mainly done by morphological methods by using morphological criteria [14]. However, this method is not sufficient for identification of damaged, engorged or immature specimens by the loss of morphological criteria or by the lack of morphological criteria $[15,16]$. Due to the limitation above, only some experienced persons have the ability to distinguish ticks accurately [17]. Molecular technique is an alternative method. PCR amplification of molecular marker has been developed and rapidly has become the essential method in the phylogenetic analyses and the species identification of ticks $[18,19,20]$. Several genetic markers, including mitochondrial $12 S$ ribosomal RNA gene (12S rDNA) [21, 22], mitochondrial 16S ribosomal RNA gene (16S rDNA) [23, 24], the second internal transcribed spacer (ITS-2) of rDNA $[25,26]$, and mitochondrial cytochrome $c$ oxidase subunit 1 (COI) [27, 28], have been widely used for the studies on ticks.

Therefore, in this study, 31 ticks collected from lizards from Xinjiang Uygur Autonomous region in China, which were difficult to be discriminated by morphological characters, were analyzed by molecular phylogeny to provide more information for further control of tick and tick-borne infectious agents in Xinjiang.

\section{Methods}




\section{Ticks collection and identification}

A total of 31 ticks were collected with tweezers from the body surface of lizard Eremias multiocellata which captured alive by hand in 4 sites of the arid desert regions in Xinjiang Uygur Autonomous region of China (Fig. 1). 47 ticks from hedgehog and 1 tick from brushwood were collected and used as reference samples [1]. The sampling localities, hosts species, ticks species and sample size of the 78 ticks used in this study were lised in Table 1. These ticks were collected and preserved separately in a 2-ml sample tube along with $2 \mathrm{ml}$ of $95 \%$ ethanol for later identification and DNA extraction. All 78 ticks were stored at the Chengdu Institute of Biology, Chinese Academy of Sciences. All of the lizards, the 78 ticks' hosts, were used in other studies. The protocol was approved by medical ethics committee of Sichuan University (No. K2018056) and carried out under the National Guidelines for Experimental Animal Welfare (MOST of People's Republic of China, 2006). 
Table 1

List of sampling localities, hosts species, ticks species and sample size in this study.

\begin{tabular}{|c|c|c|c|}
\hline $\begin{array}{l}\text { Site } \\
\text { label }\end{array}$ & Locality & Hosts & $\begin{array}{l}\text { Species and sample } \\
\text { size of ticks }\end{array}$ \\
\hline P1 & $\begin{array}{l}\text { Qiemo county, Bayingol Mongolian Autonomous } \\
\text { Prefecture, Xinjiang }\end{array}$ & & H. asiaticum (1) \\
\hline \multirow[t]{2}{*}{ P2 } & \multirow[t]{2}{*}{ Yutian county, Hotan Prefecture, Xinjiang } & \multirow[t]{2}{*}{ Hedgehog } & H. asiaticum (38) \\
\hline & & & R. turanicus (9) \\
\hline P3 & $\begin{array}{l}\text { Aheqi county, Kizilsu Kirghiz Autonomous } \\
\text { Prefecture, Xinjiang }\end{array}$ & $\begin{array}{l}\text { E. } \\
\text { multiocellata }\end{array}$ & $\begin{array}{l}\text { Haemaphysalis.sp } \\
\text { (2) }\end{array}$ \\
\hline \multirow[t]{3}{*}{ P4 } & \multirow[t]{3}{*}{$\begin{array}{l}\text { Aheqi county, Kizilsu Kirghiz Autonomous } \\
\text { Prefecture, Xinjiang }\end{array}$} & \multirow[t]{3}{*}{$\begin{array}{l}\text { E. } \\
\text { multiocellata }\end{array}$} & $\begin{array}{l}\text { Haemaphysalis.sp. } \\
\text { (4) }\end{array}$ \\
\hline & & & H. asiaticum (6) \\
\hline & & & R. turanicus (2) \\
\hline \multirow{4}{*}{$\begin{array}{l}\text { P5 } \\
\text { P6 }\end{array}$} & $\begin{array}{l}\text { Hejing county, Bayingol Mongolian Autonomous } \\
\text { Prefecture, Xinjiang }\end{array}$ & $\begin{array}{l}\text { E. } \\
\text { multiocellata }\end{array}$ & $\begin{array}{l}\text { Haemaphysalis.sp. } \\
\text { (11) }\end{array}$ \\
\hline & \multirow{3}{*}{$\begin{array}{l}\text { Xinyuan County, Ili Kazak Autonomous Prefecture, } \\
\text { Xinjiang }\end{array}$} & \multirow{3}{*}{$\begin{array}{l}\text { E. } \\
\text { multiocellata }\end{array}$} & H. asiaticum (4) \\
\hline & & & R. turanicus (1) \\
\hline & & & H. asiaticum (1) \\
\hline Total & & & 79 \\
\hline $\begin{array}{l}\text { Site } \\
\text { label }\end{array}$ & Locality & Hosts & $\begin{array}{l}\text { Species and sample } \\
\text { size of ticks }\end{array}$ \\
\hline P1 & $\begin{array}{l}\text { Qiemo county, Bayingol Mongolian Autonomous } \\
\text { Prefecture, Xinjiang }\end{array}$ & & H. asiaticum (1) \\
\hline \multirow[t]{2}{*}{ P2 } & \multirow[t]{2}{*}{ Yutian county, Hotan Prefecture, Xinjiang } & \multirow[t]{2}{*}{ Hedgehog } & H. asiaticum (38) \\
\hline & & & R. turanicus (9) \\
\hline P3 & $\begin{array}{l}\text { Aheqi county, Kizilsu Kirghiz Autonomous } \\
\text { Prefecture, Xinjiang }\end{array}$ & $\begin{array}{l}\text { E. } \\
\text { multiocellata }\end{array}$ & $\begin{array}{l}\text { Haemaphysalis.sp } \\
\text { (2) }\end{array}$ \\
\hline \multirow[t]{3}{*}{ P4 } & \multirow[t]{3}{*}{$\begin{array}{l}\text { Aheqi county, Kizilsu Kirghiz Autonomous } \\
\text { Prefecture, Xinjiang }\end{array}$} & \multirow[t]{3}{*}{$\begin{array}{l}\text { E. } \\
\text { multiocellata }\end{array}$} & $\begin{array}{l}\text { Haemaphysalis.sp. } \\
\text { (4) }\end{array}$ \\
\hline & & & H. asiaticum (6) \\
\hline & & & R. turanicus (2) \\
\hline
\end{tabular}




\begin{tabular}{|llll|}
\hline $\begin{array}{l}\text { Site } \\
\text { label }\end{array}$ & Locality & Hosts & \multicolumn{1}{c|}{$\begin{array}{l}\text { Species and sample } \\
\text { size of ticks }\end{array}$} \\
\hline P5 & $\begin{array}{l}\text { Hejing county, Bayingol Mongolian Autonomous } \\
\text { P6 }\end{array}$ & $\begin{array}{l}\text { E. } \\
\text { Pultiocellata }\end{array}$ & $\begin{array}{l}\text { Haemaphysalis.sp. } \\
(11)\end{array}$ \\
& $\begin{array}{l}\text { Xinyuan County, lli Kazak Autonomous Prefecture, } \\
\text { Xinjiang }\end{array}$ & $\begin{array}{l}\text { E. } \\
\text { multiocellata }\end{array}$ & H. asiaticum (4) \\
& & & R. turanicus (1) \\
& & & H. asiaticum (1) \\
\hline Total & & 79 \\
\hline
\end{tabular}

The ethics committee of Sichuan University is an organization under the leadership of Sichuan University. It conducts scientific and ethical review of biomedical research, public health, new drugs and new technologies in clinical research projects of Sichuan University in accordance with relevant ethical standards at home and abroad. We obtained the written consent to capture and handling of the lizards from legislation.

\section{DNA extraction, amplification, cloning and sequencing protocols}

Ticks were washed individually three times with phosphate-buffered saline (PBS, pH 7.4). Then, the half bodies of the big ticks with the width ranged from $3 \mathrm{~mm}$ to $8 \mathrm{~mm}$ were cut into small pieces with a pair of sterile scissors. The total genomic DNA was extracted for each tick with pieces of half body for big ticks or the whole bodies for small ticks with the width ranged from $1 \mathrm{~mm}$ to $2 \mathrm{~mm}$ using the commercial kit, TIANamp Genomic DNA Kit (TIANGEN Bio, Beijing, China) according to the protocols of the manufacturer. The extracted total DNA samples were stored at $-20^{\circ} \mathrm{C}$ for further use. PCR primers specific for the ticks synthesized by Tsingke Biological Technology Co., Ltd (Chengdu, China) were used to amplify 12S rDNA [21], 16S rDNA [29] and COI [27] gene fragments for each tick sample with the genomic DNA as template by PrimeSTAR Max DNA polymerase (TaKaRa Bio, Shiga, Japan) according to the manufacturer's instruction with the following cyclic condition: denaturation at $98^{\circ} \mathrm{C}$ for $10 \mathrm{~s} ; 15 \mathrm{~s}$ for annealing at specific temperature; $1 \mathrm{~min} 10 \mathrm{~s}$ for elongation at $72^{\circ} \mathrm{C}$; then repeat the three steps for 34 cycles. The negative control was treated with no template DNA and was included in all amplification run. Successful PCR products were determined by electrophoresing on a $1.5 \%$ agarose gels and purified using Universal DNA Purification Kit (TIANGEN Bio, Beijing, China). The expected product size is 320 bp of 12S rDNA, $455 \mathrm{bp}$ of $16 \mathrm{~S}$ rDNA and $760 \mathrm{bp}$ of COI. The PCR products were purified by excision of the band from agarose gel using the Universal DNA Purification Kit (TIANGEN Bio, Beijing, China) and were sequenced at Tsingke Biological Technology Co., Ltd (Chengdu, China).

\section{Sequence alignment and phylogenetic analyses}

Geneious \& prime 2019.1.3 was used to study and edit the Chromatograms. The obtained sequence data were preliminarily identified by GenBank searches done with BLASTn 
(https://blast.ncbi.nlm.nih.gov/Blast.cgi). And all the nucleotide sequences obtained in this study have been submitted to the GenBank database (S1-S3 table). The sequences were multiple-aligned with a set of ticks sequences of each locus examined in present study retrieved from the GenBank (S4-S6 Table) using ClustalW of MEGA [30] (Molecular Evolutionary Genetic Analysis v7.0.26) with its default option and refined manually. The alignments were further manually trimmed to exclude regions with missing data and then distinct sequence types (haplotypes) were defined by DAMBE v7.0.1 [31]. Then the aligned sequences were used for the following analyses. The program PartitionFinder v2.1.1 was used to choose the most appropriate models of nucleotide substitution for phylogenetic analyses using the Bayesian information criterion (BIC). Phylogenetic relationships of ticks were generated with 12S, 16S rDNA and $\mathrm{COI}$ datasets using one type of commonly applied phylogenetic method: heuristic searches using Bayesian inference (BI) with MrBayes v.3.2 [32]. In BI analyses, gaps were treated as missing data. Four Markovchains were run for 20 million generations. To avoid local optima, we used two independent runs, and to improve swapping of states between heated and cold chains the heating parameter was decreased to 0.02 . Trees were sampled every 1000 generations and the first 5000 trees were discarded as burn-in. Sampled trees were used to construct one Bayesian consensus tree and to calculate the posterior probabilities (PPs) of clades. The consensus tree was rooted at its midpoint and visualized using FigTree v.1.4.2 (available at http://tree.bio.ed.ac.uk/software/ figtree/). Argas reflexus, one species of soft ticks, was used as outgroup for $\mathrm{BI}$ analyses of $12 \mathrm{~S}$ rDNA and $A$. persicus, the other species of soft ticks, was used as outgroup for COI and 16S rDNA, respectively.

\section{Network reconstructions}

To better present the relationships among haplotypes within species, the Median joining network reconstruction method was implemented by using the program NETWORK v5.0.0.3 (available at http://www.fluxus-engineering.com/sharenet.htm).

\section{Results}

\section{Ticks samples collection from lizards.}

In total, the 31 ticks parasitized lizards (identified as E. multiocellata) were from 4 sampling sites in Xinjiang. Of these 31 ticks, 15 ticks in present study were obtained from lizards in the P5 (the intersection of two roads, S216 and G218, Xinjiang), in where all captured lizards were infested by ticks. The majority of ticks were found on the surface of lizards' armpit and crotch, and a few of ticks were found on the head, the sides of chest, or pericloaca region. The collected ticks from lizards were immature, and were very small ranged from 1 to $2 \mathrm{~mm}$ in width and with no differentiable key, which were difficult to be identified by morphological method(Fig. 2).

\section{Phylogenetic relationships}

BIC analysis conducted with the aid of jModeltest identified the HKY $+I+G$ for $12 S$ Rdna, GTR + G for $16 S$ rDNA and SYM + G, F81 + I, GTR + G for COI as the most appropriate model. The Bayesian majority rule 
consensus tree for 12S, 16S rDNA and COI are shown in Fig. 3, Fig. 4, Fig. 5, respectively.

As it showed in the Bayesian majority rule consensus tree of 12S rDNA (see Fig. 3), three clades were recovered, corresponding to the three genus Haemaphysalis, Hyalomma and Rhipicephalus. A soft tick, Argas relfexus, was used as outgroup. In Haemaphysalis, all H. sulcata ticks including 6 haplotypes (H8$\mathrm{H} 13)$ from desert $E$. multiocellata lizards cluster together $H$. sulcata from Genbank were closely related to H. cretica, although with low support. In the clade of Hy. asiaticum, $\mathrm{H} 1$ and $\mathrm{H} 3$ both shared an identical sequence to a Hy. asiaticum isolate and they were nested within 3 haplotypes $(\mathrm{H} 2, \mathrm{H} 4$ and $\mathrm{H} 5)$ with high support ( $\mathrm{PP}=1$ ). Furthermore, $\mathrm{H} 6$ shared identical sequences with $2 R$. turanicus isolate from China and clustered in a separated subclade together with H7 (PP $=0.98)$.

While in the BI tree inferred from 16S rDNA (Fig. 4), a soft tick, Argas persicus, was used as outgroup. In the clade of Haemaphysalis, 2 fragments (Q1 and Q2) from lizards (collected from P4 and P5, respectively) cluster together $(\mathrm{PP}=0.98)$ and then cluster with three fragments represented $H$. sulcata $(\mathrm{PP}=1)$. Q3 which from the hedgehog was nested with 5 sequences representing $H y$. asiaticum $(\mathrm{PP}=$ 0.98). Q4 and Q5 from the hedgehog grouped with 3 sequences representing $R$. turanicus $(\mathrm{PP}=0.97)$.

A phylogenetic tree based on COI gene of all the tick specimens is shown in Fig. 5. The results showed that, 4 haplotypes from lizards formed a strongly supported cluster with other $\mathrm{H}$. sulcata. In the clade of $R$. turanicus, one haplotype (3 sequences from lizards and 3 specimens from the hedgehog) in the present study shared identical sequences with one Chinese $R$. turanicus and were cluster with 2 sequences derived from Genbank. Notably, there are 6 haplotypes of this study and 2 sequences representing Hy. asiaticum grouped a strongly supported clade $(\mathrm{PP}=1)$.

\section{Median joining network}

To further evaluate the relationships among the intraspecific genes of 16S rDNA and COI, the MJ networks were constructed by using the Median Joining algorithm network method.

To get additional insight into the relationship with the 16SrDNA haplotypes of the genus Haemaphysalis (Fig. 6) It effectively portray that the relationship between haplotypes in this study and other species of the genus Haemaphysalis. Q1 and Q2 both collected from lizards of the Northwest of China were closely related to each other and have fewer mutation steps to $H$. sulcata than others.

The network based on COI haplotype of Rhipicephalus turanicus was shown as Fig. 7. It is showed that the $R$. turanicus from China cluster together. Z5, and other 7 sequences both from China shared the same haplotype with one from Iran (KT313117) and 2 from Kazakhstan (MN907846 and MN853166). What's more, at the intraspecific level, the haplotype network are superior to the bifurcating tree in detail that it could directly reflect the genetically small distances between the obtained haplotype Z5 in this study and other adjacent haplotypes.

Figure 8 present the MJ network based on COI haplotype of Hy. asiaticum. Apparently, The haplotype network of the Hy. asiaticum was centered around the haplotype Z7. Meanwhile, the haplotypes from 
Xinjiang cluster together. The same haplotype was shared by Z7 (11 sequences), 2 ticks from Gansu Province (MK292000 and JQ737072) and another 3 from Kazahstan (MN892553, MN961479 and MN907845). What's more, the haplotypes network of $H y$. asiaticum could intuitively reflect the distances in three obtained haplotypes. (1 mutational step).

\section{Discussion}

Generally, wild-animals serve as a huge and often unknown reservoir hosts for zoonotic disease, included tick-borne infections [33]. Many wild-animals, such as lizards, wild boars, hedgehogs, and snakes have been identified as hosts of ticks $[34,35,36]$. In reality, the study of ticks in lizards is rare, especially in China. Statistically, only 6 tick species have been reported collected from lizards in China: $A$. javanense $\triangle A$. cordiferum $\square$ A. varanense $\square$ A.crassupes $\square$ I. nipponensis and $H$. sulcata [5]. Hence, we know little about lizard-ticks. Over the past ten years, our team had obtained more than ten thousand lizards (including 6 genus, 17 species), whereas only few of them were detected tick infesting. Consequently, ticks parasitic on lizards has been identified for the first time in arid desert regions of Xinjiang in China based on molecular technique.

Consistent with the traditional taxonomy, 31 ticks from E. multiocellata-lizard of 4 sampling sites in this study belonged to 3 genera and 3 species (H.sulcata, Hy. asiaticum and R.turanicus). Similarly, 47 ticks from hedgehog and 1 from brushwood for reference also belonged to the 3 genera and 3 species. In previous studies, most of reptile-ticks are distributed in southern regions in China, which have a similar ecological environment [5]. However, In northern regions China-Xinjiang, only a particularly species H.sulcata was reported that feed on reptiles[5]. In this study, the $H$. sulcata haplotypes obtained from lizards, which based on the three genetic locus, were clustered together with the $\mathrm{H}$. sulcata sequences derived from Genbank. Meanwhile the MJ network (Fig. 6) showed that H. sulcata have shorter distance to these haplotypes than others. In this case, we can conservatively infer that 17 ticks collected from lizard has been identified to the species $\mathrm{H}$. sulcata.

Interestingly, in this study, we not only found $\mathrm{H}$. sulcate feed on lizards, but also found two local dominant species, Hy. asiaticum and R.turanicus, in Xinjiang. A previous survey of ticks from livestock also reported that H.sulcata-Hy.amasiticum and R.turanicum were found in Tarim Basin, Xinjiang. As the MJ network based on $\mathrm{COI}$ haplotype of $\mathrm{Hy}$. asiaticum showed that $\mathrm{Z7}$ shared the same haplotype with 2 ticks from Gansu and 3 from Kazakhstan (Fig. 8). The reason could be their geographical origins that Gansu and Kazakhstan border upon Xinjiang. In the meantime, there still have private lizard-tick haplotype (Z10 and Z11) in Xinjiang. In agreement with the previous surveys [8, 37], our work showed that Hy. asiaticum was the prevalent species in Xinjiang, with more than $63 \%$ of ticks in the present study. In the previous study, R. turanicus was widely distributed species in the desert and semi-desert areas in the Southern region of Xinjiang [38,39]. However, the abundance of this species seems to reduce partly due to the limit of sample size in the present study. In order to extend knowledge of tick species infesting lizards and their potential to cause tick-borne diseases, more investigations are needed. This may 
suggest that the reason why reptile-ticks are thought to be less distributed in northern China, perhaps because of a lack of research on ticks-reptiles.

Actually, thousands of lizards were captured during 2015 to 2019 in summer by our lab, which belong to the genera Eremias and Phrynocephalus from different sampling sites of the arid desert regions covered 68 counties of Xinjiang $[40,41]$ No tick was found on the lizards of other species belong to the genus Eremias and the species of Phrynocephalus, and no tick was found on the E. multiocellata-lizard from other sampling sites except for the 4 sites (P3, P4, P5 and P6), on the north of the Tarim basin. There are several factors may affect the distribution of tick species, such as the climate[Human land-use patterns $\square$ geographical habitats and hosts. The Tarim Basin, an endorheic basin in southern Xinjiang, located between Kunlun Mountais, Tianshan and Altun Mountains. Various landscapes of the Tarim Basin composed of desertification grasslandla salinized desert and an human and animals inhabit oases [39]. In conclusion, we suggest that the characteristics found in this study of ticks in Xinjiang is closely related to the geographical environment.

The ticks collected from E. multiocellata-lizard were in small size ranged from 1 to $2 \mathrm{~mm}$ in width and were immature. This phenomenon was also found in the investigation of ticks and tick-borne pathogens in the Northern Apennines that total 68 lizards were infested by immature ticks. [42]. The explanation of this phenomenon may be speculated that the immature period of most ticks was classical live in nestdwelling parasitism $[4,43]$. Lizards live in caves, even some holes extremely small. It seems that lizards should to be a suitable host for ticks which are in immature period. On the other hand, we should enlarge the sample size in future research to exclude the possibility that tick morphometric characteristics on hosts are a random sample [44].

Multiple animals are well-known vectors of ticks in the spreading mechanism of tick-borne pathogenic microorganisms. It was reported that Rickettsia raoultii has been collected from $\mathrm{H}$. erinacei parasiting marbled polecats [45]. Likewise, in China, the Theileria ovis have been identified in $R$. turanicus that collected from sheep [46]. Previously, in our team, Zhang et al. [40] had identified that lizards harbored Leishmania parasites. Therefore, we could reasonable speculate whether ticks play a role in the transmission of Leishmania [47]. Tick-borne pathogens have particular relationships with their reservoir hosts [20]. Xinjiang, adjacent to 8 countries (Russia, Kazakhstan, Kyrgyzstan, Tajikistan, Pakistan, Mongolia, India and Afghanistan), is an important transportation hub. The economic system of Xinjiang is mainly agriculture and animal husbandry, thus farmers and herdsmen are in close contact with livestock, reptiles and ticks. Therefore, the spread and epidemic risk of ticks-borne disease in this area is grim, the ability of early warning, prevention and control of tick-borne diseases should be improved.

Further studies on storage and transmission of pathogens in ticks are needed to help us control ticks and tick-borne diseases efficiently.

\section{Conclusions}


Ticks parasitic on lizards has been identified for the first time in arid desert regions of Xinjiang in China based on molecular technique. The ticks belong to 3 species and 3 genera, including $H y$. asiaticum, $R$. turanicus and $H$. sulcata. All of these ticks collected from lizard were in small size ranged from 1 to $2 \mathrm{~mm}$. Furthermore, some of these ticks share the same genotype with their counterparts in neighboring countries. The characteristic of ticks found in our study in Xinjiang is closely related to the geographical environment. Our findings might extend knowledge about tick species infesting wild-animals and help understand the relationship of lizards and ticks in Xinjiang.

\section{Abbreviations}

Hy.asiaticum: Hyalomma asiaticum; H.sulcata:Haemaphysalis sulcate, R. turanicus: Rhipicephalus turanicus.

\section{Declarations}

\section{Ethics approval and consent to participate}

The protocol was approved by medical ethics committee of Sichuan University (No. K2018056) and carried out under the National Guidelines for Experimental Animal Welfare (MOST of People's Republic of China, 2006).

\section{Consent for publication}

Not applicable.

\section{Availability of data and materials}

All data generated or analysed during this study are included in this published article [and its supplementary information files].

\section{Competing interests}

The authors declare that they have no competing interests.

\section{Funding}

This study was supported by the National Natural Science Foundation of China to XG(31672270), DC(31872959), JC(81672048), DC(31572240) and JL(31802184).

\section{Authors' contributions}


JPC, QZ, JL and DLC designed and supervised the study. HC, JHZ, JLH and ZWZ undertook the laboratory work. XGG, JLL, QS, XG and DLC collected the samples. QZ and JL wrote the manuscript. DLC, XGG and JPC revised the manuscript and polished the language. All authors read and approved the final manuscript.

\section{Acknowledgements}

Not applicable.

\section{References}

1. Parola P, Raoult D. Ticks and Tick borne Bacterial Diseases in Humans: An Emerging Infectious Threat. Clin Infect Dis. 2001;32:897-928.

2. Cupp EW. Biology of ticks. Vet Clin North Am Small Anim Pract. 1991;21:1.

3. Oliver HJ. Annual Review of Ecology and Systematics. Annu Rev Ecol Syst. 1989;20:397-430.

4. Chen Z, Yang X, Bu F, Yang X, Yang X, Liu J. Ticks (acari: ixodoidea: argasidae, ixodidae) of China. Exp Appl Acarol. 2010;51:393-404.

5. Zhang YK, Zhang XY, Liu JZ. Ticks (Acari: Ixodoidea) in China: Geographical distribution, host diversity, and specificity. Arch Insect Biochem Physiol. 2019;102:e21544. doi:10.1002/arch.21544.

6. Sheng J, Jiang M, Yang M, Bo X, Zhao S, Zhang Y, et al. Tick Distribution in border regions of Northwestern China. Ticks Tick Borne Dis. 2019;10:665-9. doi:10.1016/j.ttbdis.2019.02.011.

7. Sonenshine DE. Biology of ticks (Vol. 2). quarterly review of biology, 2014.

8. Wang YZ, Mu LM, Zhang K, Yang MH, Zhang L, Du JY. A broad-range survey of ticks from livestock in Northern Xinjiang: changes in tick distribution and the isolation of Borrelia burgdorferi sensu stricto. Parasit Vectors. 2015;8:449. doi:10.1186/s13071-015-1021-0.

9. Balasubramanian R, Yadav PD, Sahina S, Arathy Nadh V. Distribution and prevalence of ticks on livestock population in endemic area of Kyasanur forest disease in Western Ghats of Kerala, South India. J Parasit Dis. 2019;43:256-62. doi:10.1007/s12639-019-01086-7.

10. Marié JL, Davoust B, Socolovschi C, Raoult D, Parola P. Molecular detection of rickettsial agents in ticks and fleas collected from a European hedgehog (Erinaceus europaeus) in Marseilles, France. Comp Immunol Microbiol Infect Dis. 2012;35:77-9. doi:10.1016/j.cimid.2011.11.005.

11. Cerdeña J, Quequejana V, Lazo Rivera AL. First record of the hard tick, Amblyomma parvitarsum, (Acari: Ixodidae) on the, Liolaemus, (Reptilia: Squamata) lizards from Peru. INT J ACAROL. 2019:12.

12. Fang LQ, Liu K, Li XL, Liang S, Yang Y, Yao HW, et al. Emerging tick-borne infections in mainland China: an increasing public health threat. Lancet Infect Dis. 2015;15:1467-79. doi:10.1016/S14733099(15)00177-2. 
13. Zhao L, Lv J, Li F, et al. Identification and Molecular Analysis of Ixodid Ticks (Acari: Ixodidae) Infesting Domestic Animals and Tick-Borne Pathogens at the Tarim Basin of Southern Xinjiang, China. Korean J Parasitol. 2020;58(1):37-46. doi:10.3347/kjp.2020.58.1.37.

14. Li J, Chen ZH, Jiang L, Wu CY, Liao SQ, Lin XH, et al. Characterization of cattle-origin ticks from Southern China. Acta Trop. 2018;187:92-8. doi:10.1016/j.actatropica.2018.07.025. Epub 2018 Jul 25.

15. Caporale DA, Rich SM, Spielman A, Telford SR 3rd, Kocher TD. Discriminating between Ixodes Ticks by Means of Mitochondrial DNA Sequences. Mol Phylogenet Evol. 1995;4:361-5.

16. Lv J, Wu S, Zhang Y, Chen Y, Feng C, Yuan X, et al. Assessment of four DNA fragments (COI, 16S rDNA, ITS2, 12S rDNA) for species identification of the Ixodida (Acari: Ixodida). Parasit Vectors. 2014;7:93. doi:10.1186/1756-3305-7-93.

17. Jinbo U, Kato T, Ito M. Current progress in DNA barcoding and future implications for entomology. Entomol Sci. 2011;14:107-24.

18. Song S, Shao R, Atwell R, Barker S, Vankan D. Phylogenetic and phylogeographic relationships in Ixodes holocyclus and Ixodes cornuatus (Acari: Ixodidae) inferred from COX1 and ITS2 sequences. Int J Parasitol. 2011;41:871-80. doi:10.1016/j.ijpara.2011.03.008.

19. Tian Z, Liu G, Xie J, Yin H, Luo J, Zhang L, et al. Discrimination betweenHaemaphysalis longicornisandH. qinghaiensisbased on the partial 16S rDNA and the second internal transcribed spacer (ITS-2). Exp Appl Acarol. 2011;54:165-72. doi:10.1007/s10493-010-9423-3.

20. Lu X, Lin XD, Wang JB, Qin XC, Tian JH, Guo WP, et al. Molecular survey of hard ticks in endemic areas of tick-borne diseases in China. Ticks Tick Borne Dis. 2013;4:288-96. doi:10.1016/j.ttbdis.2013.01.003.

21. Beati L, Keirans JE. Analysis of the systematic relationships among ticks of the genera Rhipicephalus and Boophilus (Acari: Ixodidae) based on mitochondrial 12S ribosomal DNA gene sequences and morphological characters. J Parasitol. 2001;87:32-48.

22. Murrell A, Campbell NJ, Barker SC. Phylogenetic Analyses of the Rhipicephaline Ticks Indicate That the Genus Rhipicephalus Is Paraphyletic. Mol Phylogenet Evol. 2000;16:1-7.

23. Black WC 4th, Piesman J. Phylogeny of hard- and soft-tick taxa (Acari: Ixodida) based on mitochondrial 16S rDNA sequences. Proc Natl Acad Sci U S A. 1994;91:10034-8.

24. Norris DE, Klompen JS, Keirans JE, Black. WC 4th. Population Genetics of Ixodes scapularis (Acari: Ixodidae) Based on Mitochondrial 16S and 12S Genes. J Med Entomol. 1996;33:78-89.

25. Shaw M, Murrell A, Barker SC. Low intraspecific variation in the rRNA internal transcribed spacer 2 (ITS2) of the Australian paralysis tick,lxodes holocyclus. Parasitol Res. 2002;88:247-52.

26. Fukunaga M, Yabuki M, Hamase A, Oliver JH Jr. Nakao M. Molecular Phylogenetic Analysis of Ixodid Ticks Based on the Ribosomal DNA Spacer, Internal Transcribed Spacer 2, Sequences. J Parasitol. 2000;86:38-43.

27. Murrell A, Campbell NJH, Barker SC. Phylogenetic Analyses of the Rhipicephaline Ticks Indicate That the Genus Rhipicephalus Is Paraphyletic. Mol Phylogenet Evol. 2000;16:1-7. 
28. Mitani H, Takahashi M, Masuyama M, Fukunaga M. Ixodes philipi (Acari: Ixodidae): Phylogenetic Status Inferred from Mitochondrial Cytochrome Oxidase Subunit I Gene Sequence Comparison. J Parasitol. 2007;93:719-22.

29. Lv J, Wu S, Zhang Y, Zhang T, Feng C, Jia G, et al. Development of a DNA barcoding system for the Ixodida (Acari: Ixodida). Mitochondrial DNA. 2014;25:142-9.

30. Kumar S, Stecher G, Tamura K. MEGA7: Molecular Evolutionary Genetics Analysis version 7.0 for bigger datasets. Mol Biol Evol. 2016;33:1870-4. doi:10.1093/molbev/msw054.

31. Xuhua X. DAMBE7: New and Improved Tools for Data Analysis in Molecular Biology and Evolution. Mol Biol Evol, 2018; 6. doi:10.1093/molbev/msy073.

32. Ronquist F, Teslenko M, van der Mark P, Ayres DL, Darling A, et al. MrBayes 3.2: Efficient Bayesian Phylogenetic Inference and Model Choice Across a Large Model Space. Syst Biol. 2012;61:539-42.

33. Chomel BB, Belotto A, Meslin FX. Wildlife. Exotic Pets, and Emerging Zoonoses. Emerg Infect Dis. 2007;13:6-11.

34. Dumitrache M01, Paştiu Al, Kalmár Z, Mircean V, Sándor AD, Gherman CM, et al. Northern whitebreasted hedgehogs Erinaceus roumanicus as hosts for ticks infected with Borrelia burgdorferi sensu lato and Anaplasma phagocytophilum in Romania. Ticks Tick Borne Dis. 2013;4:214-7. doi:10.1016/j.ttbdis.2012.11.010.

35. Selmi M, Martello E, Bertolotti L, Bisanzio D, Tomassone L. Rickettsia slovaca and Rickettsia raoultii in Dermacentor marginatus ticks collected on wild boars in Tuscany, Italy. J Med Entomol. 2009;46:1490-3.

36. Dantas-Torres F, Ferreira DR, de Melo LM, Lima PA, Siqueira DB, Rameh-de-Albuquerque LC, et al. Ticks on captive and free-living wild animals in northeastern Brazil. Exp Appl Acarol. 2010;50:181-9. doi:10.1007/s10493-009-9296-5.

37. Xiang S, Gui-Lin Z, Xiao-Ming L, et al. Investigation of tick species and tick-borne pathogens in Hoxud county of Xinjiang Uyghur Autonomous Region, China. Chinese Journal of Vector Biology Control. 2013;31:1189-92.

38. Xin Y. Faunal Investigation on the Ticks in Boertala and Yili Districts of Xinjiang, China. Endemic Dis Bull. 1993;8:5.

39. Zhang GL, Zheng Z, Xiang S, et al. A survey of tick species and its distribution with the landscape structure in Xinjiang. Chinese Journal of Vector Biology Control. 2016;27:432-5.

40. Zhang JR, Guo XG, Liu JL, Zhou TH, Gong X, Chen DL, et al. Molecular detection, identification and phylogenetic inference of Leishmania spp. in some desert lizards from Northwest China by using internal transcribed spacer 1 (ITS1) sequences. Acta Trop. 2016;162:83-94. doi:10.1016/j.actatropica.2016.06.023.

41. Zhang JR, Guo XG, Chen $H$, et al. Pathogenic Leishmania spp. detected in lizards from Northwest China using molecular methods. BMC Veterinary Research. 2019; 15. doi:10.1186/s12917-019-21744. 
42. Tomassone L, Ceballos LA, Ragagli C, Martello E, De Sousa R, Stella MC, et al. Importance of Common Wall Lizards in the Transmission Dynamics of Tick-Borne Pathogens in the Northern Apennine Mountains, Italy. Microb Ecol. 2017;74:961-8. doi:10.1007/s00248-017-0994-y.

43. Balashov YS. Ixodid Ticks,Parasites and Vectors of Infections. Nauka,St.Petersburg.1998.

44. Pollock NB, Vredevoe LK, Taylor EN. How do host sex and reproductive state affect host preference and feeding duration of ticks? Parasitol Res. 2012;111:897-907. doi:10.1007/s00436-012-2916-8.

45. Guo LP, Mu LM, Xu J, Jiang SH, Wang AD, Chen CF. Rickettsia raoultii in Haemaphysalis erinacei from marbled polecats, China-Kazakhstan border. Parasit Vectors. 2015;8:461. doi:10.1186/s13071015-1065-1.

46. Song R, Wang Q, Guo F, Liu X, Song S, Chen C. Detection of Babesia spp. Theileria spp. and Anaplasma ovis in Border Regions, northwestern China. Transbound Emerg Dis. 2018;65:1537-44. doi:10.1111/tbed.12894.

47. Heyman P, Cochez C, Hofhuis A, van der Giessen J, Sprong H, Porter SR, et al. A clear and present danger: tick-borne diseases in Europe. Expert Rev Anti Infect Ther. 2010;8:33-50. doi:10.1586/eri.09.118.

\section{Figures}




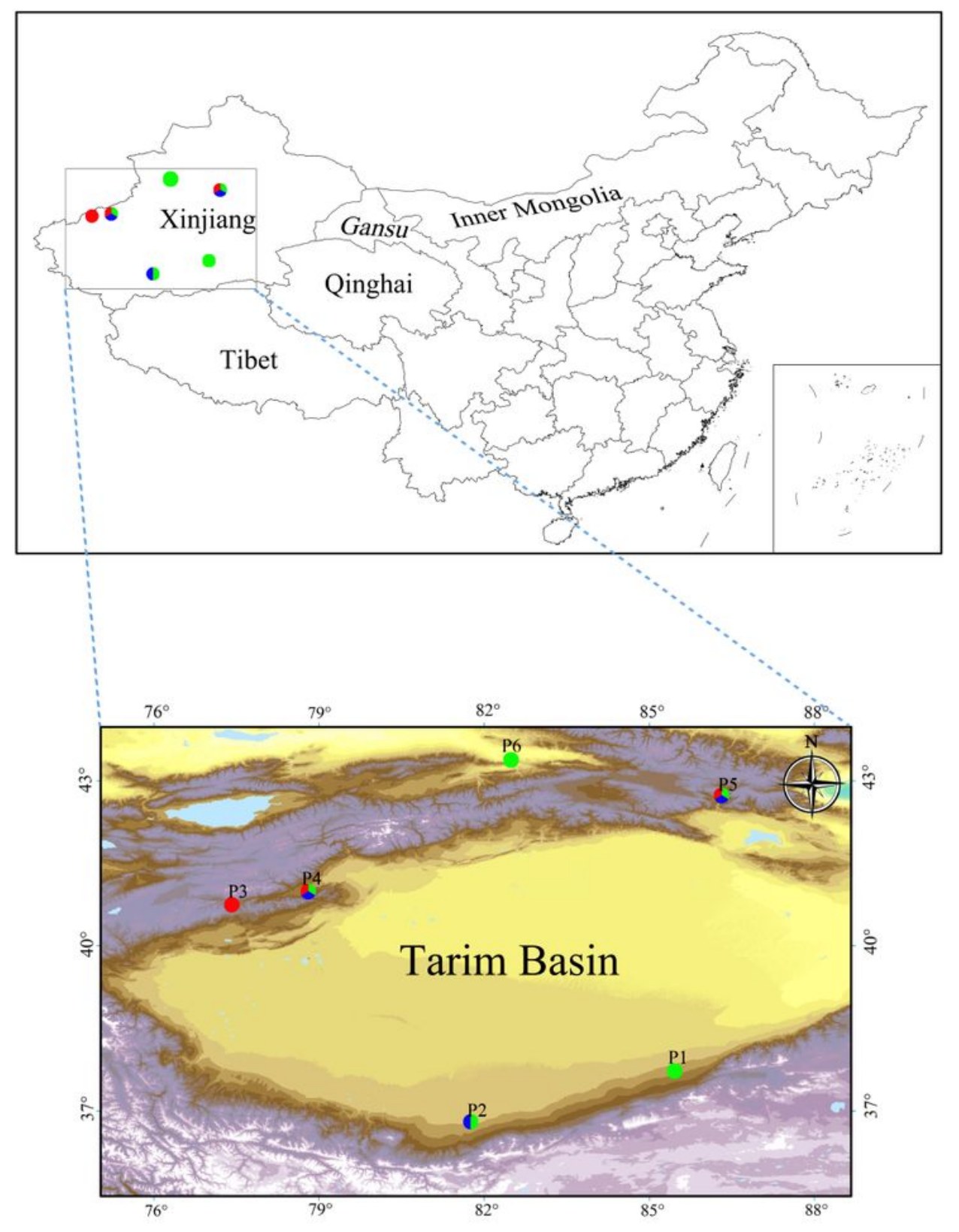

\section{Figure 1}

Sampling sites of hosts in Northwest China.The site numbers P1-P6 correspond to those in Table 1. The species of ticks collected from the sampling sites are shown for different colors (red: Haemaphysalis.sulcata, yellow: Hy. asiaticum, blue: R. turanicus). 


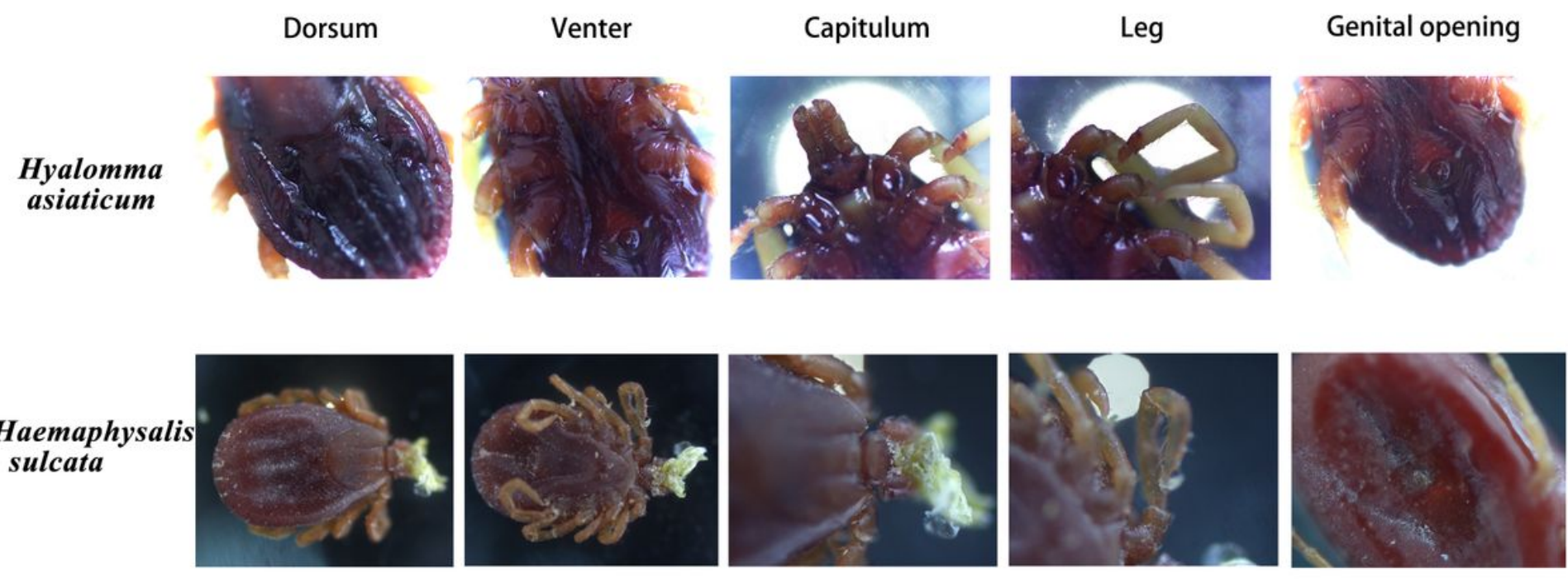

Rhipicephalus turanicus
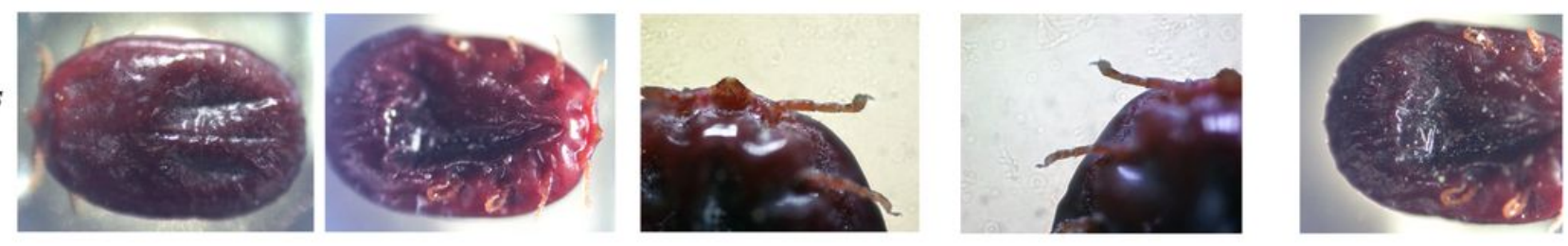

\section{Figure 2}

Photos of ticks taken by light microscope. In this study, ticks belonged to 3 species of the family Ixodidae, and showed in the column: Hy.asiaticum, H.sulcata, R.turanicus. The horizontal row showed some features of ticks: Dorsum, Venter, Capitulum, Leg, Genital opening, respectively. 


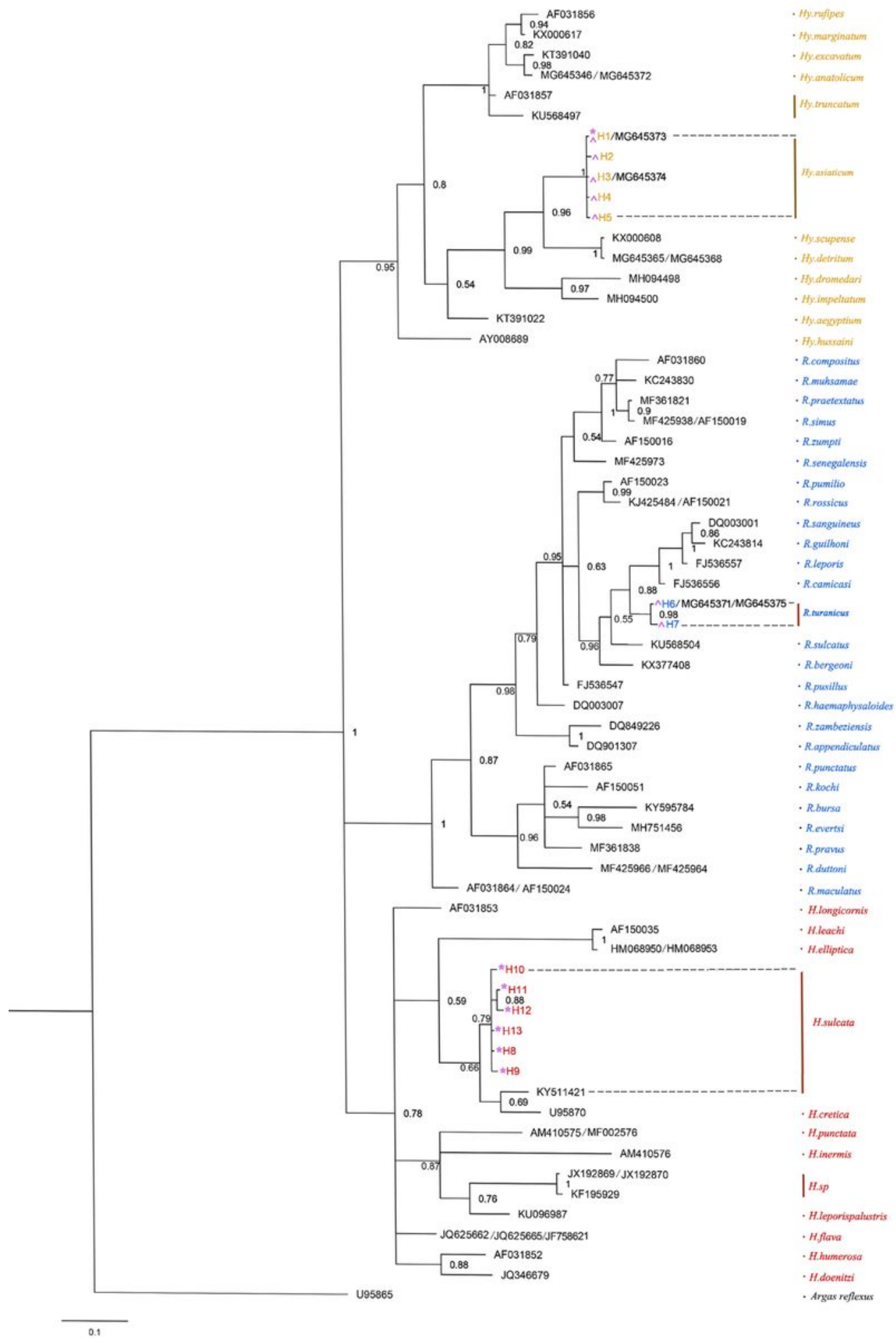

Figure 3

12S rDNA majority-rule consensus tree (midpoint rooted) inferred from Bayesian inference by using MrBayes v.3.2. Different colors represent the corresponding species obtained in this study; numbers at the nodes of the trees are the posterior probability (PP) values. * indicate the haplotype obtained from lizards, ${ }^{\wedge}$ indicate the haplotype obtained from hedgehogs. The sequences retrieved from the GenBank are shown with accession numbers and shown in S4 Table. 


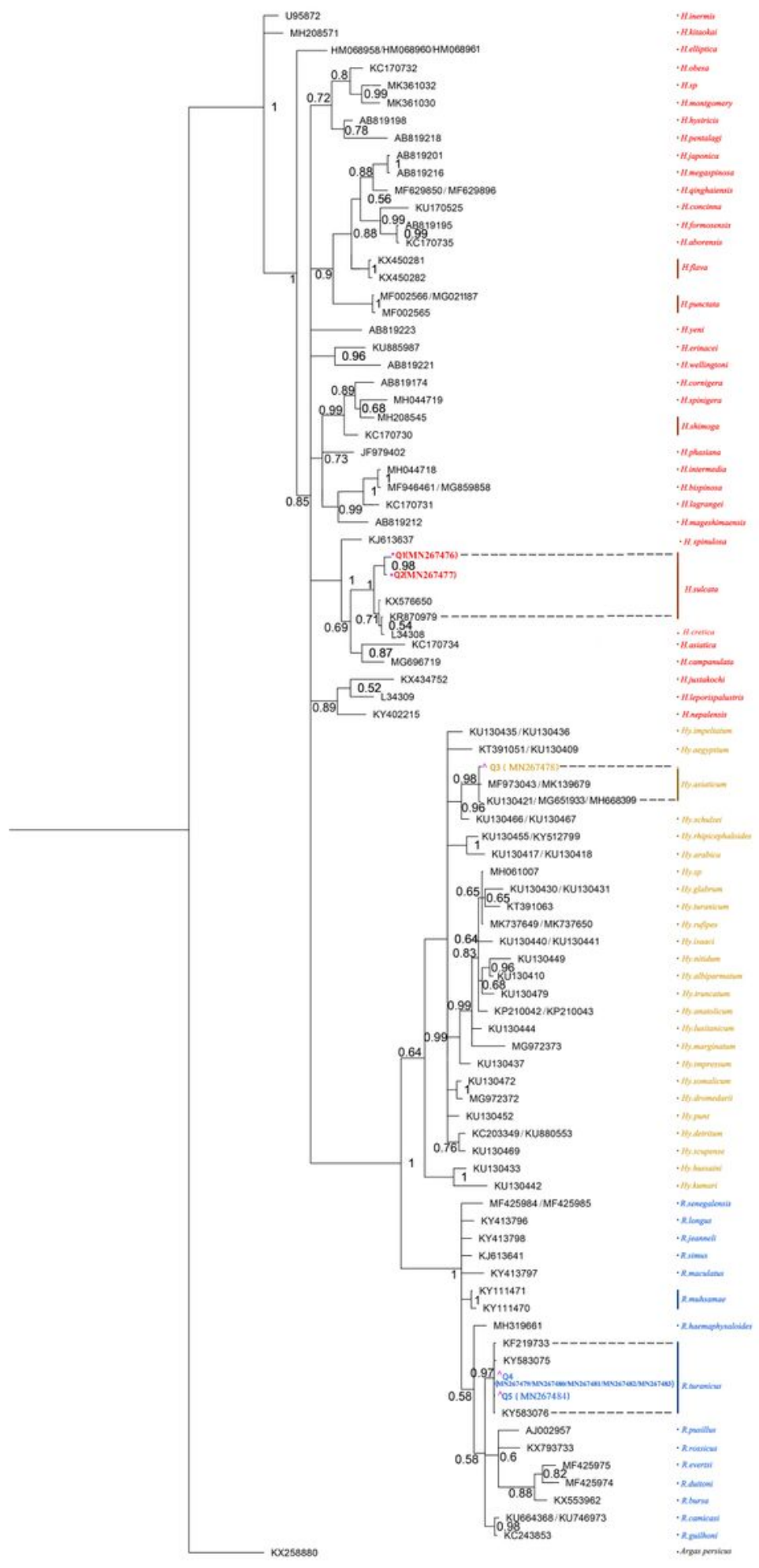

\section{Figure 4}

The majority-rule consensus tree (midpoint rooted) of 16S rDNA inferred from Bayesian inference by using MrBayes v.3.2. Different colors represent the corresponding species obtained in this study; numbers at the nodes of the trees are the posterior probability (PP) values. * indicate the haplotype obtained from lizards, ${ }^{\wedge}$ indicate the haplotype obtained from hedgehogs. The sequences retrieved from the GenBank were shown with accession numbers shown in S5 Table. 


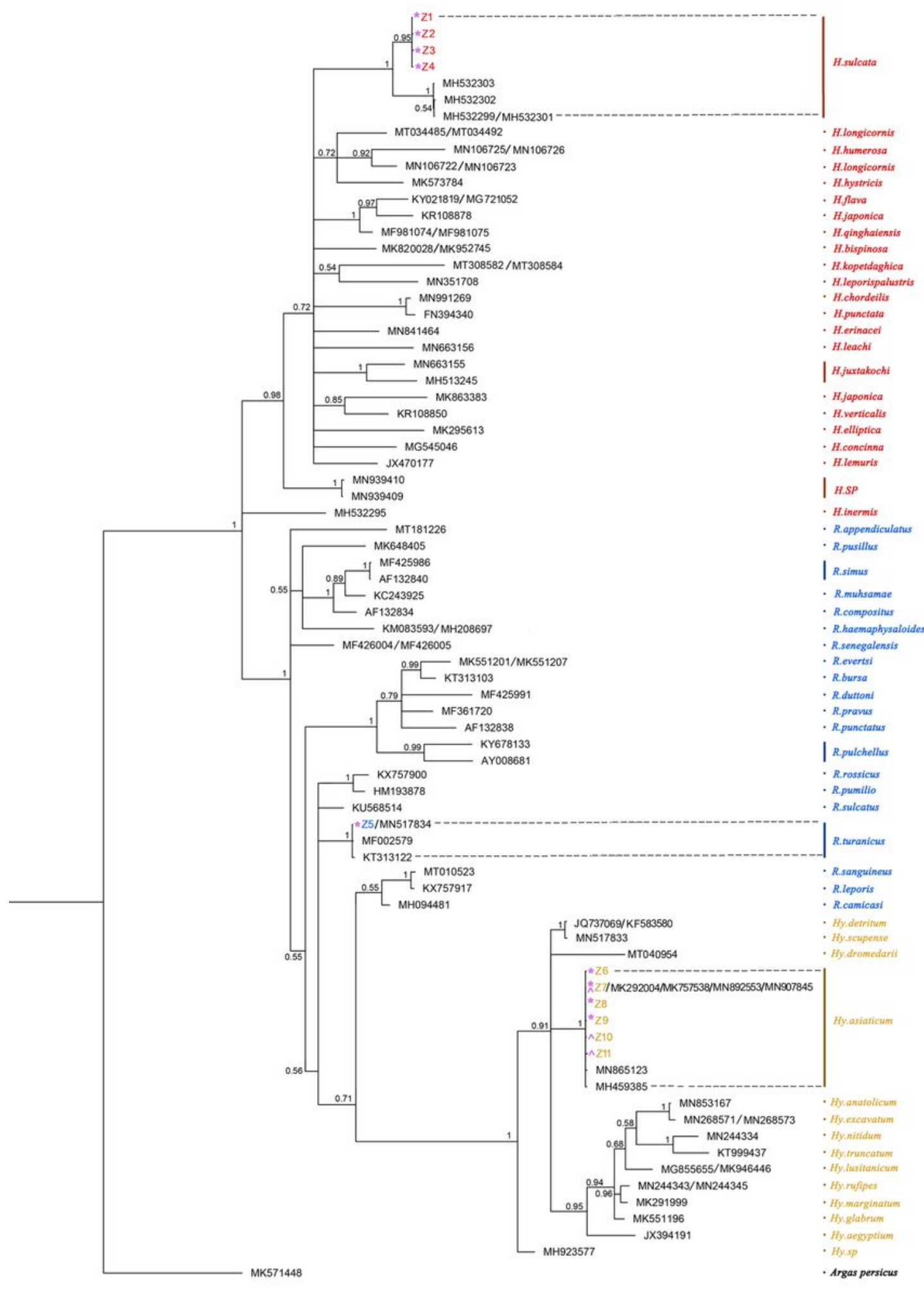

\section{Figure 5}

The majority-rule consensus tree (midpoint rooted) of $\mathrm{COI}$ inferred from Bayesian inference by using MrBayes v.3.2. Different colors represent the corresponding species obtained in this study; numbers at the nodes of the trees are the posterior probability (PP) values. * indicate the haplotype obtained from lizards, ${ }^{\wedge}$ indicate the haplotype obtained from hedgehogs. The sequences retrieved from the GenBank were shown with accession numbers shown in S6 Table. 


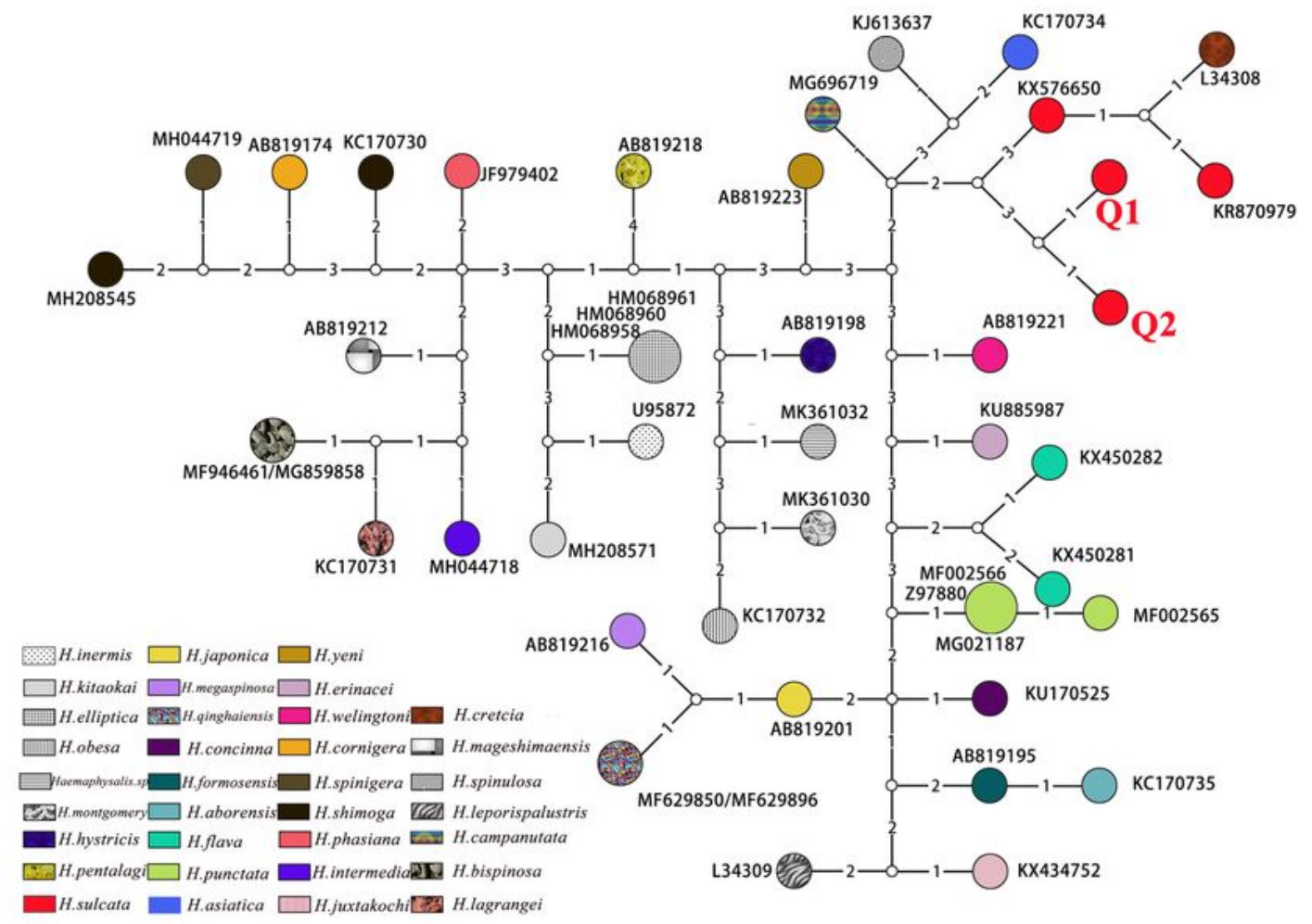

\section{Figure 6}

Median-joining network based on 16S rDNA haplotype of Haemaphysalis sulcata. implemented by using NETWORK v5.0.0.3. Circles of the networks indicate the haplotypes and small hollow circles indicate median vectors inferred by NETWORK software. Colors of circles represent the species of the genus Haemaphysalis. The size of the circles roughly represents the numbers of sequences carrying the haplotype, with the scale given beside the network. The information of reference sequences see S5 Table. 


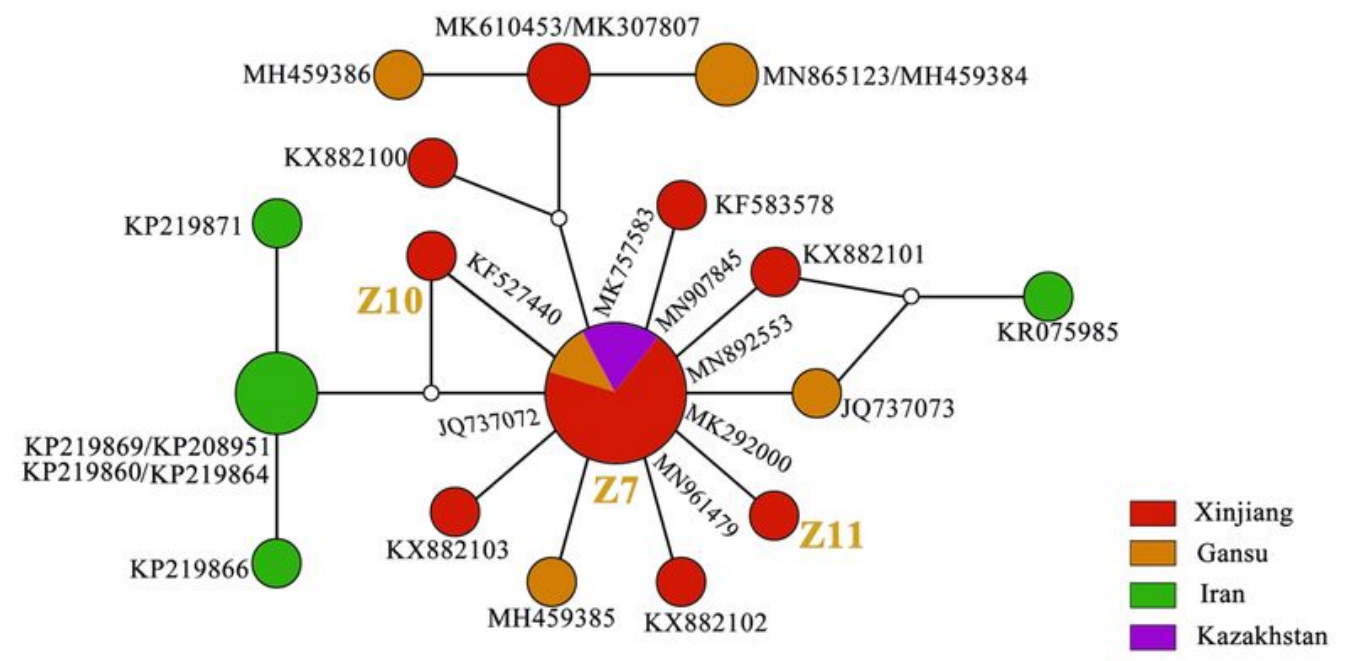

\section{Figure 7}

Median-joining network based on COI haplotype of Rhipicephalus turanicus (Z5) implemented by using NETWORK v5.0.0.3. Circles of the networks indicate the haplotypes and small hollow circles indicate median vectors inferred by NETWORK software. The size of the circles roughly represents the numbers of sequences carrying the haplotype, with the scale given beside the network. Different filled patterns 
represent the corresponding geographical origin from which the haplotype was sampled. The information of reference sequences see S7 Table.

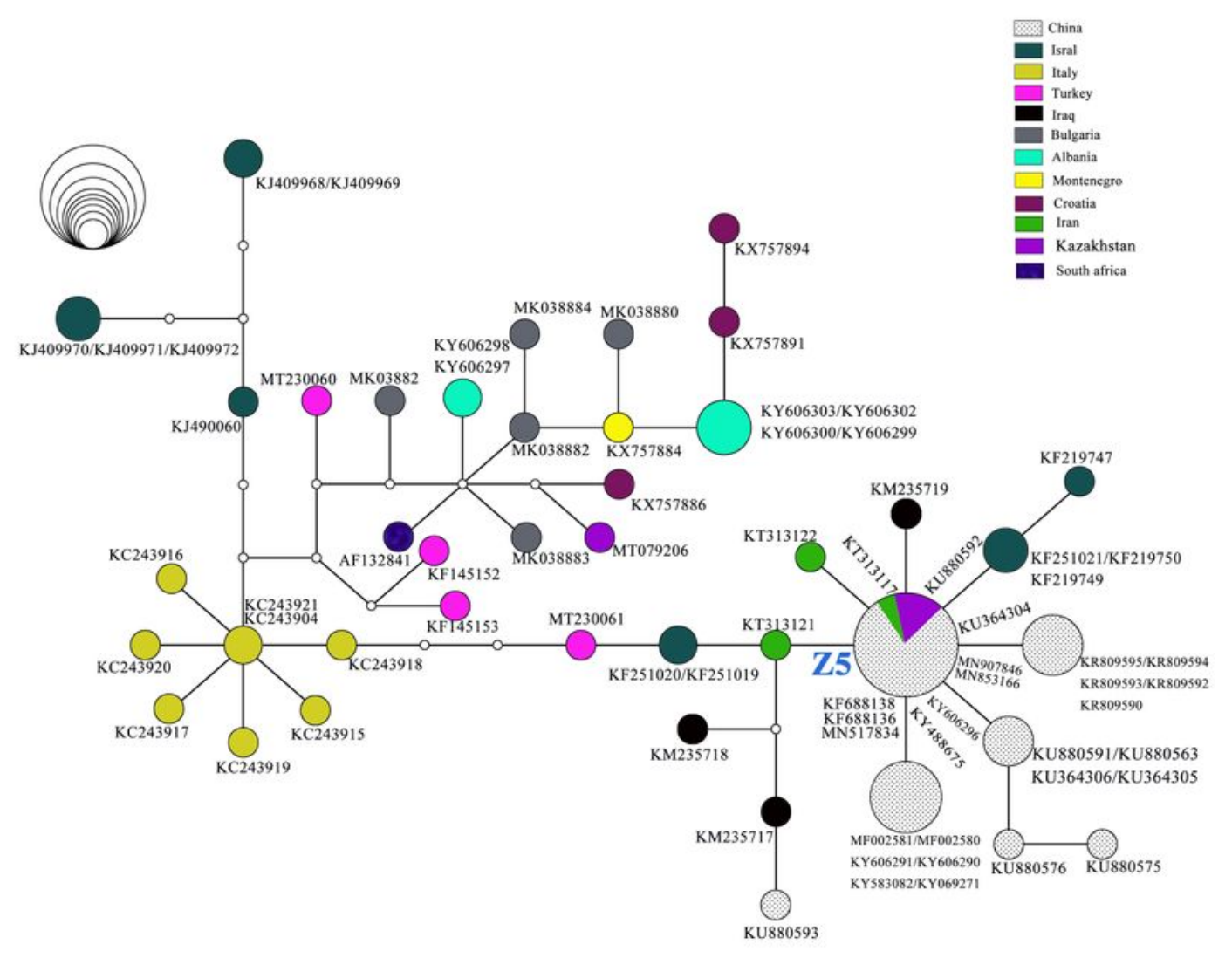

Figure 8

Median-joining network based on COI haplotype of Hyalomma asiaticum implemented by using NETWORK v5.0.0.3. Circles of the networks indicate the haplotypes and small hollow circles indicate median vectors inferred by NETWORK software. The size of the circles roughly represents the numbers of 
sequences carrying the haplotype, with the scale given beside the network. different filled patterns represent the corresponding geographical origin from which the haplotype was sampled. The information of reference sequences see S8 Table.

\section{Supplementary Files}

This is a list of supplementary files associated with this preprint. Click to download.

- Graphicalabstract.jpg

- coverletterZQ.docx

- Supprtinginformation.doc 